Eur. J. Clin. Chem. Clin. Biochem.

Vol. 30, 1992, pp. $363-369$

(C) 1992 Walter de Gruyter \& Co. Berlin $\cdot$ New York

\title{
Determination of Lipid Hydroperoxides in Serum Iodometry and High Performance Liquid Chromatography Compared
}

\author{
By E. Wieland, V. Schettler*, F. Diedrich, P. Schuff-Werner and M. Oellerich \\ Abteilung Klinische Chemie, Zentrum Innere Medizin, Georg-August-Universität Göttingen, Göttingen, Germany
}

(Received November 4, 1991/April 7, 1992)

Summary: It is postulated that lipid peroxidation plays a role in the pathogenesis of a variety of diseases. Efforts have therefore been made to develop reliable and practicable procedures for quantifying lipid peroxidation products such as lipid hydroperoxides in biological specimens. An iodometric cholesterol colour reagent (Merck, Darmstadt, Germany) can be used to measure lipid hydroperoxides in isolated low density lipoproteins without lipid extraction. This method has been validated with respect to its analytical performance and suitability for serum samples by comparing it with a high performance liquid chromatography technique. The method was found to have acceptable performance characteristics with aqueous fatty acid hydroperoxide solutions (linoleic acid) and isolated low density lipoproteins, but it cannot be applied to native serum samples without extraction of lipids.

\section{Introduction}

Lipid peroxidation has attracted considerable attention during recent years $(1-3)$. It has been linked to carcinogenesis (4), aging (5) and to a variety of other diseases including atherosclerosis (6). The oxidative modification of low density lipoproteins in particular is considered an important factor in the development of atherosclerotic vascular lesions $(7,8)$.

The peroxidation of unsaturated fatty acids is a radical chain reaction which is initiated by the abstraction of a hydrogen atom from a methylene group of the fatty acid chain. The carbon radical formed by this reaction tends to stabilize by molecular rearrangement leading to conjugated double bounds. By the reaction with oxygen a reactive peroxy radical is generated which can abstract a hydrogen atom from another lipid molecule. This propagation stage of lipid peroxidation leads to the formation of cytotoxic hydroperoxides (9). On heating or with metal catalysts these lipid hydroperoxides are broken down to lipid alkoxy and peroxy radicals, initiating further radical chain

* This work is part of the doctoral thesis of V. Schettler. reactions. Lipid alkoxy radicals are particularly prone to the so-called beta cleavage reaction, leading to the formation of cytotoxic and genotoxic aldehydes (10).

The commonly used thiobarbituric acid method measures these aldehydic products of lipid peroxidation. It is relatively non-specific and is also unreliable in biological samples such as serum (11). More specific assays have recently been developed to quantify lipid peroxidation products, among which luminometric techniques coupled to high performance liquid chromatography have proved to be reliable for the measurement of lipid hydroperoxides (12-14). However, these techniques are time consuming and require sample preparation and special equipment, thereby hampering their application to routine measurements.

A simple and specific spectrophotometric method for following the formation of lipid hydroperoxides during the in vitro oxidation of low density lipoproteins by copper ions was recently reported by El Saadani et al. (15). The method is based on the oxidation of iodide to iodine by lipid hydroperoxides, uses commercially available reagents (cholesterol colour reagent, Merck, Darmstadt, Germany), and does not 
require extraction of lipoprotein lipids. However, the authors neither validated their method with respect to standard lipid solutions nor to serum samples. The objective of the present study was to investigate whether the method is reliable and can be applied to biological samples such as human serum without extraction. For this purpose we compared it with a high performance liquid chromatography technique using chemiluminescence detection for the quantification of lipid hydroperoxides (14).

\section{Materials and Methods}

Reagents

Ascorbic acid, linoleic acid, glycine, phenylalanine, tyrosine, methionine, lysine, arginine, cysteine, histidine, tryptophan, asparagine, glutamine, aspartic acid, glutamic acid, proline, poly-proline, poly-cysteine, poly-histidine, poly-methionine, poly-tryptophan, poly-phenylalanine, apolipoprotein B100, transferrin, butylated hydroxy toluene, and lipoxidase (linoleate: oxygen oxidoreductase from soyabean, EC 1.13.11.12) ${ }^{1}$ ) were purchased from Sigma Chemical Co. St. Louis Mo. USA. $\mathrm{H}_{2} \mathrm{O}_{2}$ (Perhydrol ${ }^{\circledR}$ ), cholesterol colour reagent (CHOD-iodide method), chloroform, triton-X-100, sodium azide, alkylbenzyldimethylammonium chloride, iron(II) sulphate, copper(II) sulphate 5-hydrate, ammonium heptamolybdate, potassium hydrogenphosphate, potassium dihydrogenphosphate, butanol, methanol, hydrochloric acid $(5 \mathrm{~mol} / \mathrm{l})$, sodium hydroxide $(5 \mathrm{~mol} / \mathrm{l})$, and boric acid were from Merck, Darmstadt, Germany. Ethanol was from J. T. Baker B. V., Deventer, The Netherlands. Human albumin was from Behringwerke AG, Marburg, Germany. All reagents were analytical grade.

\section{Blood samples}

Serum samples were obtained from freshly drawn venous blood specimens. Collection tubes did not contain any anticoagulant but were prepared with the antioxidant, butylated hydroxy toluene, in order to avoid non-specific peroxidation. For this purpose a $10 \mathrm{mmol} / \mathrm{l}$ stock solution of butylated hydroxy toluene was prepared in ethanol and $10 \mu \mathrm{l}$ of this solution were added to the collection tubes prior to blood sampling. Tubes were filled with $10 \mathrm{ml}$ blood to yield a final butylated hydroxy toluene concentration of $100 \mu \mathrm{mol} / \mathrm{l}$. For recovery experiments multiple samples were combined to obtain a serum pool.

\section{Isolation of low density lipoproteins}

Low density lipoproteins were isolated by ultracentrifugation as described by Havel (15). Low density lipoproteins were kept under nitrogen during the whole isolation procedure in order to protect the lipoprotein lipids against non-specific peroxidation. For this purpose all solutions were saturated with nitrogen before and after ultracentrifugation and the isolated low density lipoprotein preparations were dialysed against a nitrogen saturated TRIS-HCl buffer ( $5 \mathrm{mmol} / \mathrm{l}, \mathrm{pH}$ 7.4) containing $1 \mathrm{mmol} / \mathrm{l}$ EDTA.

\footnotetext{
1) Enzyme

Lipoxidase:

1.13.11.12)
}

\section{Oxidation of lipids}

\section{Linoleic acid}

Linoleic acid was oxidized using lipoxidase as previously described (14). Two hundred microliters of stock solution corresponding to $20 \mathrm{mg}$ linoleic acid (stock solution: $100 \mathrm{~g}$ linoleic acid per litre $\mathrm{CHCl}_{3}$ ) were evaporated under $\mathrm{N}_{2}$ and resuspended in $2 \mathrm{ml}$ borate buffer $(50 \mathrm{mmol} / 1, \mathrm{pH} 9.4)$. Lipoxidase $(815 \mathrm{U})$ was added in 6 aliquots $(10 \mu \mathrm{l})$ every $10 \mathrm{~min}$ during $1 \mathrm{~h}$ of incubation at $37^{\circ} \mathrm{C}$ in a shaking water bath. At the end of incubation the oxidized fatty acid was extracted twice with $2 \mathrm{ml}$ diethyl ether at acidic $\mathrm{pH}(20 \mu \mathrm{l} 5 \mathrm{~mol} / \mathrm{l} \mathrm{HCl})$. The ether phases were combined and evaporated under $\mathrm{N}_{2}$ and the oxidized fatty acid was redissolved in ethanol at the desired concentrations and stored at $-20^{\circ} \mathrm{C}$.

\section{Serum samples}

Serum samples $(2 \mathrm{ml})$ were incubated in a shaking water bath at $37^{\circ} \mathrm{C}$ for $120 \mathrm{~min}$. Lipoxidase $(746.9 \mathrm{kU})$ dissolved in 5.5 $\mathrm{ml}$ borate buffer $(50 \mathrm{mmol} / \mathrm{l}, \mathrm{pH} \mathrm{9.3)}$ was added in 7 aliquots $(50 \mu \mathrm{l})$ every $5 \mathrm{~min}$ during the first $30 \mathrm{~min}$ of incubation and then in 6 additional aliquots $(50 \mu \mathrm{l})$ every $10 \mathrm{~min}$ over the next $60 \mathrm{~min}$. Incubations were stopped by cooling $\left(0^{\circ} \mathrm{C}\right)$. Control incubations with borate buffer instead of lipoxidase were run in parallel.

\section{Low density lipoproteins}

Low density lipoproteins ( $1 \mathrm{~g}$ protein per litre) were oxidized by $\mathrm{CuSO}_{4}$. For this purpose low density lipoproteins were dialysed $\left(5 \mathrm{~h}, 20^{\circ} \mathrm{C}\right)$ against EDTA-free TRIS-HCl buffer ( $5 \mathrm{mmol} / \mathrm{l}, \mathrm{pH} 7.4$ ) containing $20 \mu \mathrm{mol} / 1 \mathrm{CuSO}_{4}$ as described by Jürgens et al. (17).

\section{Extraction of lipids}

Lipid extraction was performed by the Bligh \& Dyer procedure (18). The chloroform layer was evaporated under $\mathrm{N}_{2}$ and the dried lipid residue was redissolved in ethanol.

\section{Iodometric assay}

Lipid hydroperoxide determination with the iodometric assay (cholesterol colour reagent, cholesterol oxidase-iodide method, Merck, Darmstadt, Germany) was performed as described by El Saadani et al. (15). Lipids were added in ethanol to the reagent mixture. Blank readings were made after the addition of pure ethanol. $\mathrm{H}_{2} \mathrm{O}_{2}$ was diluted with $\mathrm{H}_{2} \mathrm{O}$ and analysed at the indicated concentrations. Samples were incubated at room temperature for either $30 \mathrm{~min}$ or $60 \mathrm{~min}$ in the dark.

Amino acids $(1 \mathrm{~g} / \mathrm{l})$, polypeptides $(1 \mathrm{~g} / \mathrm{l})$, albumin $(1 \mathrm{~g} / \mathrm{l})$, apolipoprotein $\mathrm{B} 100(1 \mathrm{~g} / \mathrm{l}), \mathrm{Fe}_{2} \mathrm{SO}_{4}(250 \mu \mathrm{mol} / \mathrm{l})$, and $\mathrm{CuSO}_{4}(250$ $\mu \mathrm{mol} / \mathrm{l})$ were dissolved in water and $100 \mu \mathrm{l}$ of these samples were also mixed with $1 \mathrm{ml}$ of the reagent mixture. Ascorbic acid was dissolved in water and was added at the indicated concentrations together with $40 \mu \mathrm{mol} / 1 \mathrm{H}_{2} \mathrm{O}_{2}$ or oxidized low density lipoproteins.

A "blank" reagent mixture without iodine, prepared according to the manufacturer's instructions, consisted of $0.15 \mathrm{mmol} / 1$ sodium azide, $2 \mathrm{~g} / \mathrm{l}$ triton-X-100, $0.1 \mathrm{~g} / \mathrm{l}$ alkylbenzyldimethylammonium chloride, and $0.01 \mathrm{mmol} / 1$ ammonium heptamolybdate in a potassium phosphate buffer $(0.2 \mathrm{~mol} / 1, \mathrm{pH} 7.0)$.

Absorbances were determined at $365 \mathrm{~nm}$ with a Beckman DU8 spectrophotometer (Beckman Instruments, Irvine, CA, USA). Wavelength scanning between $250 \mathrm{~nm}$ and $450 \mathrm{~nm}$ was performed with the same instrument. Lipid hydroperoxide and 
$\mathrm{H}_{2} \mathrm{O}_{2}$ concentrations were calculated using a molar extinction coefficient of $2.46 \cdot 10^{3} \mathrm{~m}^{2} / \mathrm{mol}$ and $2.45 \cdot 10^{3} \mathrm{~m}^{2} / \mathrm{mol}$ respectively as published by El Saadani et al. (15).

High performance liquid chromatography determination of lipid hydroperoxides

For measurement of lipid hydroperoxides by high performance liquid chromatography we modified a method originally described by Frei et al. (12). For the luminometric detection of hydroperoxides, a modification of an assay cocktail originally published by Myiazawa et al. (13) was used. The modified cocktail consisted of $6.4 \mu \mathrm{mol} / 1$ cytochrome $\mathrm{c}$ and $0.1 \mu \mathrm{mol} / \mathrm{l}$ luminol. Two columns ( $\mathrm{Si} 60$ and ODS RP) were combined in order to increase the separation performance (14). Reduced ubiquinone has been shown to cause hydroperoxide non-specific signals in the luminescence detection described by Frei et al. (12), but it does not interfere in our assay (14). For the quantification of the lipid hydroperoxides by high performance liquid chromatography, integrated peak areas were compared with peak areas obtained with an external linoleic acid hydroperoxide standard. The amount of hydroperoxide contained in this standard fatty acid was determined iodometrically (15).

\section{Other assays}

Protein was determined by the Lowry procedure (19). Cholesterol measurements in serum and low density lipoprotein samples were performed enzymatically using the peroxidase/4-aminophenazone technique (Boehringer Mannheim, Mannheim, Germany). Bilirubin was determined according to Jendrassik \& Grof (20) using a commercially available reagent kit (Boehringer Mannheim, Mannheim, Germany) and an automatic analyser (Hitachi 717, Boehringer Mannheim, Mannheim, Germany).

Reducing substances contained in serum samples were determined with a commercially available test kit (Boehringer Mannheim, Mannheim, Germany) which is based on the reduction of the tetrazolium salt 3-(4,5 dimethylthiazolyl-2)-2,5-diphenyltetrazolium bromide to formazan.

\section{Recovery experiments}

Hydroperoxides were determined in serum samples which had been spiked with oxidized low density lipoproteins. They were also determined in serum samples without added oxidized low density lipoproteins, as well as in oxidized low density lipoproteins alone. For this purpose $300 \mu \mathrm{l}$ of a serum pool were mixed with $200 \mu \mathrm{l}$ of an oxidized low density lipoprotein preparation, resulting in a total sample volume of $500 \mu$. The volume of the serum samples which were not spiked with oxidized low density lipoproteins and the volume of the oxidized low density lipoprotein preparation itself was also corrected to $500 \mu \mathrm{l}$ with sodium chloride $(0.9 \mathrm{~g} / \mathrm{l})$. Samples were assayed by the iodometric method, either directly or after extraction. For the high performance liquid chromatography detection of hydroperoxides, samples $(500 \mu \mathrm{l})$ were extracted with $500 \mu \mathrm{l}$ butanol

\section{Results}

Iodide oxidation as measured by the iodometric method is linearly related to the hydroperoxide concentration up to at least $40 \mu \mathrm{mol} / \mathrm{l}$ of either $\mathrm{H}_{2} \mathrm{O}_{2}$ or linoleic acid hydroperoxides (fig. 1). Linoleic acid concentrations above $250 \mu \mathrm{mol} / \mathrm{l}$ caused turbidity thus precluding hydroperoxide measurement.

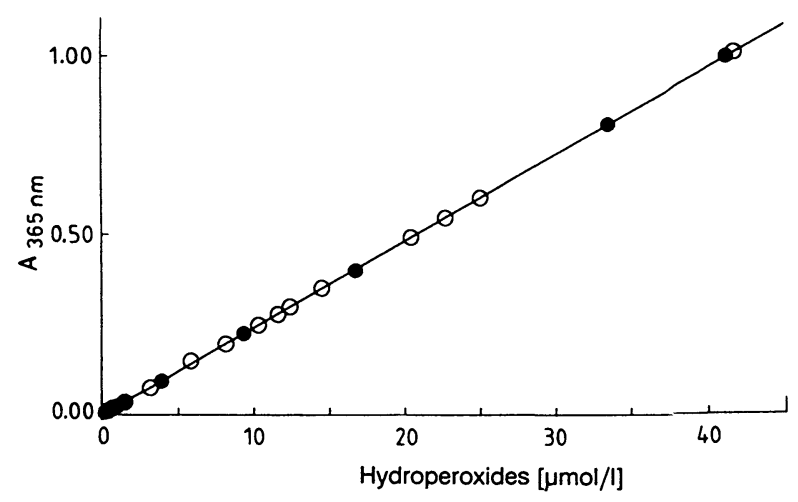

Fig. 1. Relationship between absorbance at $365 \mathrm{~nm}$ (iodometric method), hydrogen peroxide (open symbols) and linoleic acid hydroperoxide (closed symbols) concentrations. Samples were treated as described in Materials and Methods. Values are means of duplicate determinations. The linoleic acid contained $0.16 \mu \mathrm{mol}$ hydroperoxide per mol fatty acid.

Within day and day to day imprecision of the iodometric method is summarized in table 1.

With oxidized lipid samples the incubation time of 30 min was not sufficient to complete the reaction. It took at least $60 \mathrm{~min}$ at room temperature before the conversion of iodide to iodine was complete with 50 $\mu \mathrm{mol} / 1$ linoleic acid hydroperoxide or $40 \mu \mathrm{mol} / 1$ low density lipoprotein lipid hydroperoxide (fig. 2).

When serum samples were analysed iodometrically, interindividual absorbance differences $(365 \mathrm{~nm})$ were observed $(\overline{\mathrm{x}} \pm \mathrm{s}: \quad 0.23 \pm 0.01$; range: $0.11-0.34$ $\mathrm{n}=30$ ).

In order to investigate whether these absorbances were hydroperoxide-specific, other serum components such as proteins (albumin, apolipoprotein B100), amino acids, polypeptides or metal ions (copper, iron), which have been suggested to interfere with iodometry

Tab. 1. Imprecision of the iodometric method.

\begin{tabular}{|c|c|c|c|c|}
\hline Type of imprecision & Sample & $\mathrm{n}$ & $\begin{array}{l}\overline{\mathrm{x}} \pm \mathrm{s} \\
(\mu \mathrm{mol} / \mathrm{l})\end{array}$ & $\begin{array}{l}\text { CV } \\
(\%)\end{array}$ \\
\hline Within day & $\begin{array}{l}\text { LDL lipid hydroperoxides } \\
\text { Linoleic acid hydroperoxides }\end{array}$ & $\begin{array}{l}20 \\
20\end{array}$ & $\begin{array}{r}13.25 \pm 0.47 \\
5.13 \pm 0.53\end{array}$ & $\begin{array}{r}3.5 \\
10.3\end{array}$ \\
\hline Day to day & $\begin{array}{l}\text { LDL lipid hydroperoxides } \\
\text { Linoleic acid hydroperoxides }\end{array}$ & $\begin{array}{l}5 \\
5\end{array}$ & $\begin{array}{r}12.48 \pm 1.23 \\
7.40 \pm 1.48\end{array}$ & $\begin{array}{r}9.8 \\
20.0\end{array}$ \\
\hline
\end{tabular}




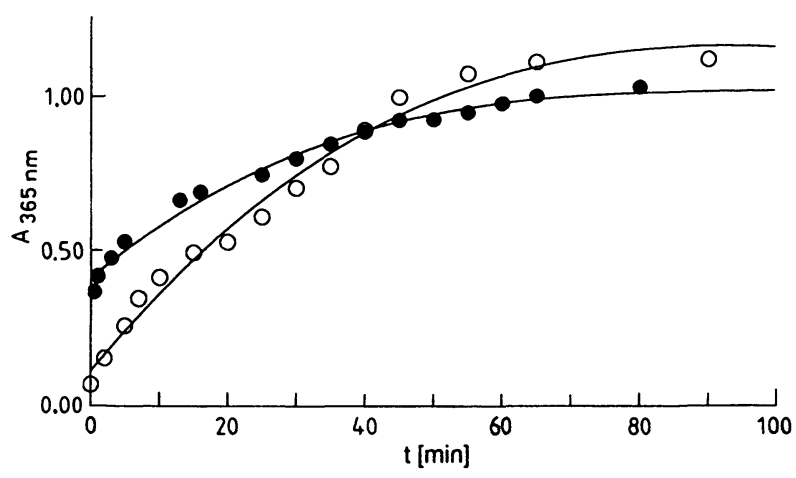

Fig. 2. Kinetics of iodine oxidation using either low density lipoprotein lipid hydroperoxide (closed symbols) or linoleic acid hydroperoxide (open symbols). Samples were incubated as described in Material and Methods. Values are means of duplicate determinations. The linoleic acid contained $0.2 \mu \mathrm{mol}$ hydroperoxide per mol fatty acid.

(21), were tested in the assay at the concentrations given in Materials and Methods. Of the compounds tested only an aqueous solution of ferrous sulphate (250 $\mu \mathrm{mol} / \mathrm{l})$ caused a change in absorbance $(0.1)$ during $60 \mathrm{~min}$ of incubation. Copper ions did not react at a concentration of $250 \mu \mathrm{mol} / 1$. Transferrin was also ineffective in catalysing the oxidation of iodide.

No increase of absorbance ( $365 \mathrm{~nm}$ ) was found during a 60 min incubation of serum samples with the iodometric reagent $\left(\mathrm{A}_{60 \min }-\mathrm{A}_{0 \min }=\overline{\mathrm{x}} \pm \mathrm{s}: \quad 0.01\right.$ \pm 0.01 ; range: $0.00-0.04 ; n=30$ ). This was not due to the antioxidant, butylated hydroxytoluene, contained in serum samples, since up to $100 \mu \mathrm{mol} / \mathrm{l} \mathrm{bu}$ tylated hydroxytoluene were without effect on the oxidation of iodide by $11 \mu \mathrm{mol} / 1$ linoleic acid hydroperoxide.

In order to confirm that the absorbance differences seen between serum samples were independent of the oxidation of iodide by hydroperoxides, a reaction mixture without iodide was prepared according to the manufacturer's instructions (Merck, Darmstadt, Germany). Addition of serum samples to this "blank" reagent mixture also caused absorptions which were not different from those obtained with the same samples using the complete colour reagent $\left(\mathrm{A}_{60 \text { min }}-\mathrm{A}_{0 \text { min }}\right.$ $=\overline{\mathrm{x}} \pm \mathrm{s}: 0.01 \pm 0.01$; range: $0.00-0.04 ; \mathrm{n}=30$ ). Control incubations with $40 \mu \mathrm{mol} / 1 \mathrm{H}_{2} \mathrm{O}_{2}$ or $33 \mu \mathrm{mol} / 1$ linoleic acid hydroperoxides caused no absorbance at $365 \mathrm{~nm}$ with this "blank" reagent mixture.

Further evidence that the absorbances obtained with the iodometric reagent and serum samples were not due to the oxidation of iodide by hydroperoxides is provided by wavelength scanning between $250 \mathrm{~nm}$ and $450 \mathrm{~nm}$. Whereas $20 \mu \mathrm{mol} / 1 \mathrm{H}_{2} \mathrm{O}_{2}$ caused a peak at $365 \mathrm{~nm}$ with the iodometric reagent, no such peak

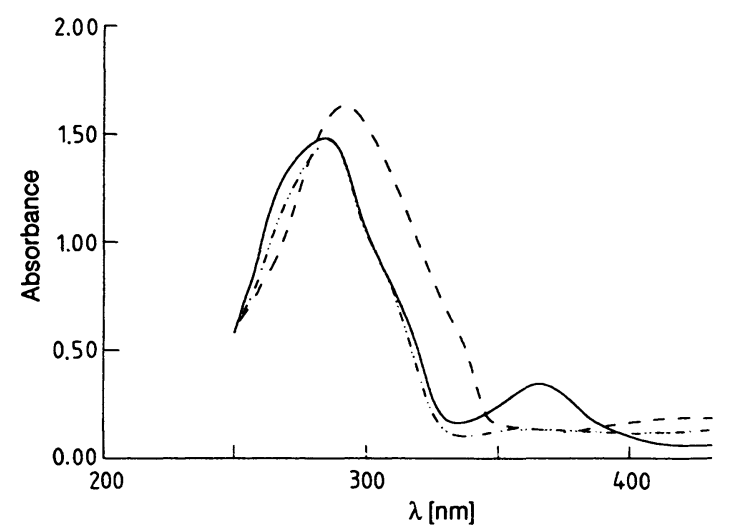

Fig. 3. Wavelength scanning (250 nm-450 nm) of serum (dashed line), $20 \mu \mathrm{mol} / 1$ hydrogen peroxide (solid line), and $5 \mu \mathrm{mol} / 1 \beta$-carotene (dashed and dotted line) incubated for $60 \mathrm{~min}$ with the iodometric reagent. Experimental details were as described in Materials and Methods.

was observed with a serum sample showing an absorbance of 0.20 , which theoretically corresponds to $8.1 \mu \mathrm{mol} / 1$ lipid hydroperoxide (fig. 3). $\beta$-Carotene $(5 \mu \mathrm{mol} / \mathrm{l})$, which is found in low density lipoproteins (22), also absorbed (0.21) at $365 \mathrm{~nm}$ (fig. 3). Nonspecific absorbances of serum samples were not related to serum bilirubin concentrations $(r=0.08$; $p>0.05 ; n=20$ ), or to triacylglycerol concentrations $(\mathrm{r}=0.4 ; \mathrm{p}>0.05 ; \mathrm{n}=20)$, but showed a weak positive and significant correlation with serum total cholesterol $(\mathrm{r}=0.5 ; \mathrm{p}<0.05 ; \mathrm{n}=20)$, and low density lipoprotein cholesterol $(\mathrm{r}=0.5 ; \mathrm{p}<0.05$; $\mathrm{n}=20$ )

Serum samples did not contain lipid hydroperoxides, as shown by the high performance liquid chromatography method. Figure 4 shows the high performance liquid chromatographic analysis of serum samples with and without addition of an oxidized low density lipoprotein preparation. Lipid hydroperoxides were seen predominantly in the cholesterol ester fraction of the oxidized low density lipoprotein preparation (fig. 4). The exogenously added low density lipoprotein lipid hydroperoxides were not detectable iodometrically unless the lipids were extracted (tab. 2). Peroxidation of serum lipids was also induced enzymatically in 9 serum samples using lipoxidase. In contrast to the high performance liquid chromatography method, these enzymatically generated endogenous lipid hydroperoxides were not reliably measured with the iodometric method (fig. 5). The yield of lipid hydroperoxides iodometrically recovered from serum was inversely related to the reducing capacity of serum samples which was determined by the reduction of the tetrazolium salt 3-(4,5 dimethylthiazolyl-2)-2,5diphenyltetrazolium bromide (MTT) $(r=-0.67$, $\mathrm{p}<0.1, \mathrm{y}=-7.99 \mathrm{x}+1.67)$. 


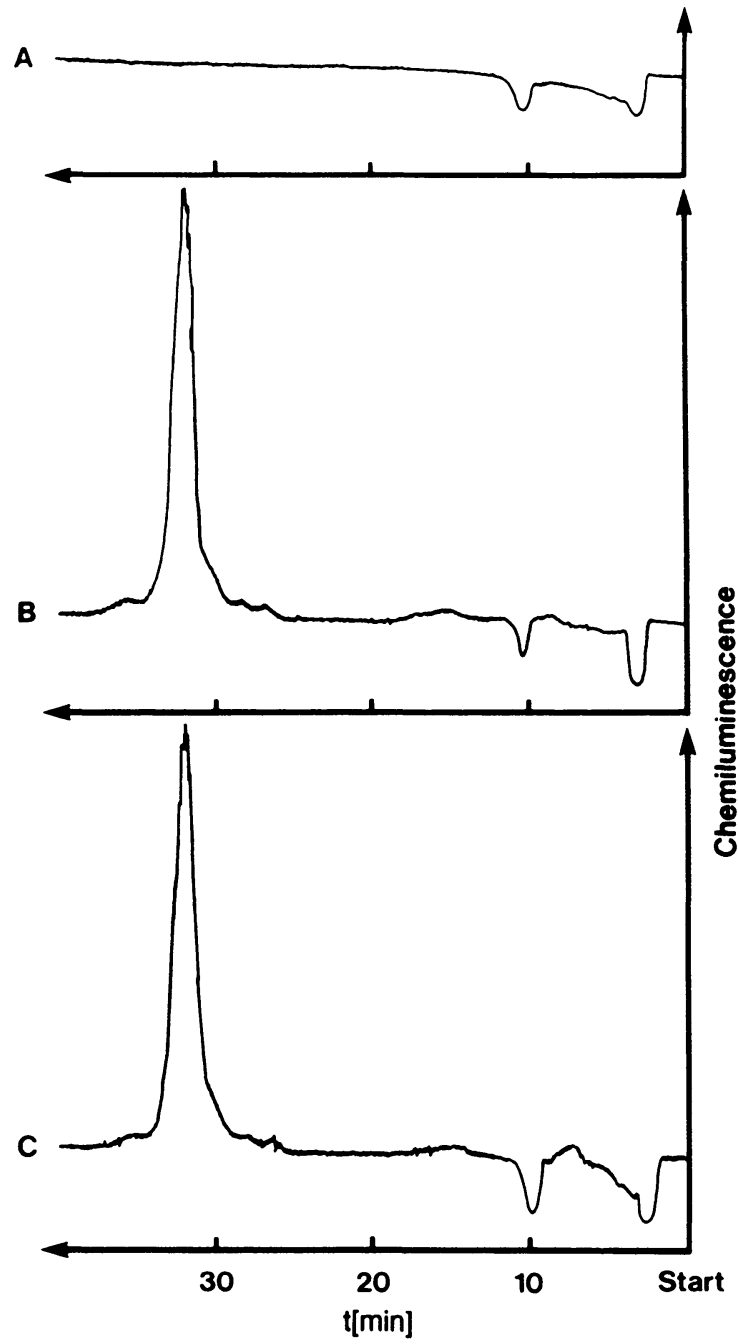

Fig. 4. High performance liquid chromatography separation of a butanol extract from native serum (chromatogram A), an oxidized low density lipoprotein preparation (chromatogram B) and the oxidized low density lipoprotein preparation added to serum (chromatogram C). $\alpha$-tocopherol elutes after 10 min (negative signal), cholesterol ester hydroperoxides after $32 \mathrm{~min}$ (positive signal). Experimental details were as described in Materials and Methods.

Physiological concentrations of ascorbic acid (60 $\mu \mathrm{mol} / \mathrm{l})$ reduced the iodometric signal obtained with $\mathrm{H}_{2} \mathrm{O}_{2}(40 \mu \mathrm{mol} / \mathrm{l})$ and oxidized low density lipoproteins $(5.4 \mu \mathrm{mol} / \mathrm{l})$. High concentrations of ascorbic

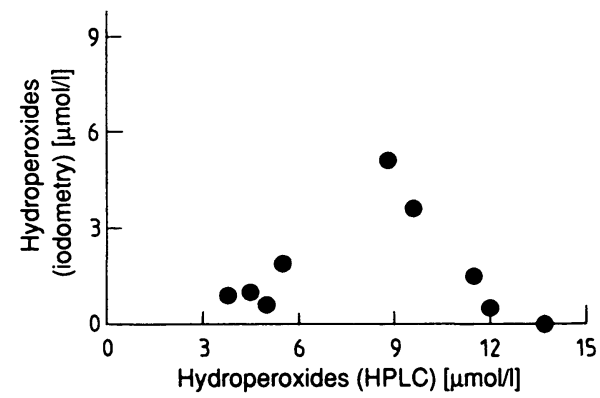

Fig. 5. Comparison between the iodometric method and the high performance liquid chromatography method. Lipid hydroperoxides were generated in serum $(n=9)$ by lipoxidase treatment as described in Materials and Methods. Values are means of duplicate determinations.

acid $(280 \mu \mathrm{mol} / \mathrm{l})$ totally precluded iodometric measurements (tab. 3). Ascorbic acid had the same effect, irrespective of whether it was added before or after incubation of hydroperoxides with the iodometric reagent (tab. 3).

\section{Discussion}

The importance of lipid peroxidation in biological systems has been recognized during recent years $(1-11)$. Efforts are being made to develop reliable and practicable methods to measure lipid peroxidation products such as lipid hydroperoxides in biological specimens $(11-15)$. The oxidation of iodide to iodine by hydroperoxides has been frequently used to determine lipid peroxidation $(21,23-25,26)$. El Saadani et al. have used a commercially available iodometric reagent mixture to monitor the formation of low density lipoprotein lipid hydroperoxides in vitro (15). This assay is convenient and easy to use. However, it has not been shown whether this method is reliable, and whether it can also be applied to biological samples other than lipoprotein preparations such as serum. This iodometric method was therefore compared with a high performance liquid chromatography method (14).

Tab. 2. Recovery of LDL lipid hydroperoxides from serum samples added as oxidized low density lipoprotein lipids - comparison between iodometry and HPLC.

\begin{tabular}{lllll}
\hline \multirow{2}{*}{ Method } & \multicolumn{2}{l}{ Lipid hydroperoxides $(\mu \mathrm{mol} / \mathrm{l})$} & \multirow{2}{*}{ Recovery } \\
\cline { 2 - 5 } & Serum & LDL & Serum + LDL & $0 \%$ \\
\hline Iodometry without extraction & $<1$ & 36.0 & $<1$ & $74,3 \%$ \\
Iodometry with extraction & $<1$ & 35.0 & 26.0 & $94.6 \%$ \\
\hline HPLC & $<1$ & 37.0 & 35.0 & 9 \\
\hline
\end{tabular}

Values are means of duplicate determinations from one representative experiment. 
Tab. 3. Effect of ascorbic acid on the iodometric method.

Ascorbic acid was added before and after a $60 \mathrm{~min}$ incubation of either $40 \mu \mathrm{mol} / 1$ hydrogen peroxide $\left(\mathrm{H}_{2} \mathrm{O}_{2}\right)$ or $5.4 \mu \mathrm{mol} / 1$ low density lipoprotein lipid hydroperoxide with the iodometric colour reagent.

Sample

$\mathrm{H}_{2} \mathrm{O}_{2}$

$\mathrm{H}_{2} \mathrm{O}_{2}$ plus $60 \mu \mathrm{mol} / 1$ ascorbic acid

$\mathrm{H}_{2} \mathrm{O}_{2}$ plus $280 \mu \mathrm{mol} / \mathrm{l}$ ascorbic acid

$\mathrm{H}_{2} \mathrm{O}_{2}$ plus $60 \mu \mathrm{mol} / \mathrm{l}$ ascorbic acid

$\mathrm{H}_{2} \mathrm{O}_{2}$ plus $280 \mu \mathrm{mol} / \mathrm{l}$ ascorbic acid

LDL

LDL plus $60 \mu \mathrm{mol} / 1$ ascorbic acid

LDL plus $280 \mu \mathrm{mol} / 1$ ascorbic acid

LDL plus $60 \mu \mathrm{mol} / 1$ ascorbic acid

LDL plus $280 \mu \mathrm{mol} / \mathrm{l}$ ascorbic acid before incubation before incubation after incubation

after incubation

before incubation before incubation after incubation after incubation
Hydroperoxides measured $(\mu \mathrm{mol} / \mathrm{l})$

$$
\begin{aligned}
40.0 & \pm 0.5 \\
34.5 & \pm 0.7 \\
& <1 \\
35.0 & \pm 0.7 \\
& <1 \\
5.4 & \pm 0.6 \\
2.4 & \pm 0.7 \\
& <1 \\
2.7 & \pm 0.6 \\
& <1
\end{aligned}
$$

Values are given as means $\pm s, n=5$.

The iodometric assay is not specific for hydroperoxides, since iron in an aqueous solution can also lead to the oxidation of iodide. However, iron is transported in serum tightly bound to transferrin and ironsaturated transferrin did not cause any signal with the reagent. It is therefore unlikely that serum metals interfere with the assay.

Absorbances observed at $365 \mathrm{~nm}$ with serum samples were non-specific and independent of the oxidation of iodine. Serum samples caused no time-related increase in absorbance at $365 \mathrm{~nm}$ and the incubation of serum samples with a "blank" reagent without iodide caused almost the same absorbances as those obtained with the complete iodometric reagent.

Lipid hydroperoxides added to serum in the form of an oxidized low density lipoprotein preparation were not detected iodometrically unless the lipids were extracted (tab. 2). Lipid hydroperoxides, enzymatically generated in serum samples by lipoxidase treatment, were also not reliably detectable with the iodometric which can react with the iodine formed. 1 or ciample, ascorbic acid, which has a redox potential lower than method (fig. 5). This is possibly due to the presence of reducing activity, which was detected in serum, and iodine $\left(\mathrm{E}_{\mathrm{o}}=0.085 \mathrm{~V}\right.$ vs. $\left.\mathrm{E}_{\mathrm{o}}=0.535 \mathrm{~V}\right)$, decreased the iodometric signal at physiological concentrations, while at high concentrations it totally precluded iodometric measurement of $\mathrm{H}_{2} \mathrm{O}_{2}$. This interference was caused by the reduction of the iodine already formed by the oxidation of iodide in the presence of hydroperoxides (tab. 3). Other reducing substances such as glutathione or uric acid, which we did not investigate, may have similar effects.

The high performance liquid chromatography method shows hydroperoxides predominantely in the cholesterol ester fraction of oxidized serum and low density lipoproteins (fig. 4). This is in agreement with data of Frei et al., who used a similar high performance liquid chromatography method and found that cholesterol ester and phospholipid hydroperoxides in particular are stable in human plasma (27).

The non-specific absorbances seen with serum at 365 $\mathrm{nm}$ were not related to bilirubin and triacylglycerol concentrations, but showed a positive and significant correlation with total cholesterol and low density lipoprotein cholesterol levels. Similar non-specific absorbance readings were observed with $\beta$-carotene (fig. 3 ) which is transported in lipoproteins (22). The limited lipid dissolving capacity of the iodometric reagent, which we have observed with linoleic acid or isolated low density lipoproteins, causes minor turbidities which may also contribute to non-specific background absorbances. Neither albumin, nor apolipoprotein B100, nor a variety of polypeptides and amino acids were found to interfere with the iodometric assay at the concentrations tested.

As previously suggested by Thomas et al. (21) and Cramer et al. (26) the present results confirm that it is necessary to extract lipid hydroperoxides from serum before running an iodometric assay. Cramer et al. (26) report $4.0 \pm 1.7 \mu \mathrm{mol} / 1$ hydroperoxides in extracted human plasma samples using their iodometric method, whereas we were not able to detect lipid hydroperoxides in serum with the high performance liquid chromatography method (fig. 4). This is in agreement with Frei et al., who also found no lipid hydroperoxides in human plasma using a similar chemiluminescence high performance liquid chromatography assay (12). The discrepancies might be due to the lack of protection against oxidation employed during blood sampling and storage. Cramer et al. analysed pooled plasma samples which had been frozen and thawed without added antioxidants (26). Fur- 
thermore, the possibility cannot be excluded that individuals whose antioxidant defenses are depleted might develop circulating lipid hydroperoxides.

The results of this investigation show that the method published by El Saadani et al. (15) is a reliable tool to monitor lipid hydroperoxides in isolated lipoprotein preparations. However, the incubation time of 30 min is not sufficient and should be increased to at least $60 \mathrm{~min}$. Most importantly the method cannot be used for native serum samples without extraction. In addition, the iodometric assay has a relatively unfa-

\section{References}

1. Sies, H. (1986) Biochemie des oxidativen Stress. Angew. Chem. 98, 1061-1075.

2. Yagi, K. (1987) Lipid Peroxides and Human Diseases. Chem. Phys. Lipids 45, 337-351.

3. Weber, G. F. (1990) The measurement of Oxygen-Derived Free Radicals and Related Substances in Medicine. J. Clin. Chem. Clin. Biochem. 28, 569-603.

4. Sodum, R. S. \& Chung, F. L. (1991) Stereoselective Formation of in Vitro Nucleic Acid Adducts by 2,3-Epoxy-4Hydroxynonenal. Cancer Res. 51, 137-143.

5. Cutler, R. G. (1991) Antioxidants and Aging. Am. J. Clin. Nutr. 53, 373-379.

6. Piotrowski, J. J., Hunter, G. C., Eskelson, C. D., Dubick, M. A. \& Bernhard, V. M. (1990) Evidence for Lipid Peroxidation in Atherosclerosis. Life Sci. 46, 715-721.

7. Steinberg, D., Parthasarathy, S., Carew, T., Khoo, J. C. \& Witztum, J. L. (1989) Beyond Cholesterol. Modifications of Low Density Lipoprotein that Increase its Atherogenicity. New Engl. J. Med. 320, 915-924.

8. Parthasarathy, S., Wieland, E. \& Steinberg, D. (1989) A Role for Endothelial Cell Lipoxygenase in the Oxidative Modification of Low Density Lipoprotein. Proc. Natl. Acad. Sci. USA 86, 1046-1050.

9. Michiels, C. \& Remacle, J. (1991) Cytotoxicity of Linoleic Acid Peroxide, Malondialdehyde and 4-Hydroxynonenal Towards Human Fibroblasts. Toxicology 66, 225-234.

10. Esterbauer, H. \& Zollner, H. (1989) Methods for Determination of Aldehydic Lipid Peroxidation Products. Free Rad. Biol. Med. 7, 197-203.

11. Gutteridge, J. M. C. \& Halliwell, B. (1990) The Measurement and Mechanism of Lipid Peroxidation in Biological Systems. Trends in Biochem. Sciences 15, 129-135.

12. Frei, B., Yamamoto, Y., Niclas, D. \& Ames, B. D. (1988) Evaluation of an Isoluminol Chemiluminescence Assay for the Detection of Hydroperoxides in Human Blood Plasma. Anal. Biochem. 174, 120-130.

13. Myiazawa, T. (1989) Determination of Phospholipid Hydroperoxides in Human Blood Plasma by a Chemiluminescence-HPLC Assay. Free Rad. Biol. Med. 7, 209-217.

14. Wieland, E., Diedrich, F., Niedmann, P. D. \& Seidel, D. (1991) Measurement of Free Fatty Acid, Phospholipid, Triglyceride, and Cholesterol Ester Hydroperoxides by a CL-HPLC Method. In: Bioluminescence and Chemiluminescence. Current Status. (Stanley, P. E. \& Kricka, L. J., eds.) pp. 235-238, John Wiley and Sons, Chichester.

15. El Saadani, M., Esterbauer, H., El-Sayed, M., Goher, M. Nassar, A. Y. \& Jürgens, G. (1989) A Spectrophotometric Assay for Lipid Peroxidation in Serum Lipoproteins Using a Commercially Available Reagent. J. Lipid. Res. 30, 627630.

16. Havel, R. J., Eder, H. A. \& Bragdon, J. H. (1955) The Distribution and Chemical Composition of Ultracentrifugally Separated Lipoproteins in Human Serum. J. Clin. Invest. $43,1345-1353$. vourable detection limit $(1 \mu \mathrm{mol} / \mathrm{l})$ compared with the high performance liquid chromatography methods (about $0.05 \mu \mathrm{mol} / \mathrm{l}) 12-14$ ). This will also hamper its application in the investigation of tissue samples and membranes where only low concentrations of lipid hydroperoxides can be expected $(28,29)$.

\section{Acknowledgement}

The authors wish to thank Mrs. Ulrike Bonitz for expert technical assistance and Priv.-Doz. Dr. V. W. Armstrong for fruitful discussions and careful reading of the manuscript.

17. Jürgens, G., Hoff, H. F., Chisolm, G. M. \& Esterbauer, H (1987) Modification of Human Serum Low Density Lipoprotein by Oxidation - Characterization and Pathophysiological Implications. Chem. Phys. Lipid 45, 315-336.

18. Bligh, E. H. \& Dyer, W. J. (1955) A Rapid Method of Total Lipid Extraction and Purification. Can. J. Biochem. Physiol. $37,911-917$.

19. Lowry, O. H., Rosebrough, N. J., Farr, A. L. \& Randall, R. J. (1951) Protein Measurement with the Folin Phenol Reagent. J. Biol. Chem. 193, 265-275.

20. Jendrassik, L. \& Grof, P. (1938) Vereinfachte photometrische Methoden zur Bestimmung des Bilirubins. Biochem. Z. 297, 81-89.

21. Thomas, S. M., Jessup, W., Gebicki, J. M. \& Dean, R. T. (1989) A Continous-Flow Automated Assay for Iodometric Estimation of Hydroperoxides. Anal. Biochem. 176, $353-$ 359.

22. Esterbauer, H., Rothendeder, M., Striegel, G., Waeg, G., Ashy, A., Sattler, W. \& Jürgens, G. (1989), Vitamin E and Other Lipophilic Antioxidants Protect LDL Against Oxidation. Fat Sci. Technol. 8, 316-356.

23. Asakawa, T. \& Matsushita, S. (1978) Colorimetric Determination of Peroxide Value with Potassium Iodide-Silica Gel Reagent. J. Am. Oil. Chem. Soc. 55, 619-620.

24. Gebicki, J. M. \& Guille, J. (1989) Spectrophotometric and High-Performance Chromatographic Assays of Hydroperoxides by the Iodometric Technique. Anal. Biochem. 176, $360-364$.

25. Oette, K., Peterson, M. L. \& McAuley, R. L. (1963) A Highly Sensitive Method for Measurement of Lipid Hydroperoxides by Iodometry and Amperometric Endpoint. J. Lipid. Res. 4, 212-215.

26. Cramer, G. L., Miller, J. F. Jr., Pendleton, R. B. \& Lands, W. E. M. (1991) Iodometric Measurement of Lipid Hydroperoxides in Human Plasma. Anal. Biochem. 193, 204211.

27. Frei, B., Stocker, R. \& Ames, B. N. (1988) Antioxidant Defenses and Lipid Peroxidation in Human Blood Plasma. Proc. Natl. Acad. Sci. USA 85, 9748-9752.

28. Thomas, J. P. \& Girotti, A. W. (1989) Reactivity of Photochemically-Generated Lipid Hydroperoxides in Cell Membranes with Glutathione Peroxidase. Photochem. Photobiol. $49,153-156$.

29. Thomas, S. M., Gebicki, J. M. \& Dean, R. T. (1989) Radical Initiated $\alpha$-Tocopherol Depletion and Lipid Peroxidation in Mitochondrial Membranes. Biochim. Biophys. Acta 1002, 189-197.
Dr. med. Eberhard Wieland
Zentrum Innere Medizin
Abteilung Klinische Chemie
Georg-August-Universität
Robert-Koch-Straße 40
W-3400 Göttingen
Bundesrepublik Deutschland 
